CESIS Electronic Working Paper Series

Paper No. 215

\title{
An Investigation of the Causal Relations between Exchange Rates and Interest Rates Differentials using Wavelets
}

R. Scott Hacker, Huynjoo Kim and Kristofer Månsson

Jönköping International Business School

February 2010 


\title{
An Investigation of the Causal Relations between Exchange Rates and Interest Rate Differentials Using Wavelets
}

R. Scott Hacker, Hyunjoo Kim, and Kristofer Månsson

Department of Economics

Jönköping International Business School (JIBS)

P.O.Box 1026 SE-551 Jönköping, Sweden

\section{This Version}

January 7 th, 2010

\begin{abstract}
Monthly and quarterly data for the spot exchange rate of the Swedish Krona against major currencies have been used in this paper to investigate the causality in a Granger sense at different time scales between the spot exchange rate and the nominal interest rate differential by using wavelet analysis. Impulse response functions are also utilized to examine the signs of how one of these variables affects the other over time. One key empirical finding from the causality tests is that there is only substantial evidence of a causal relationship in the long run between the two variables. When using monthly data, this is true in both directions. When considering impulse responses on how the interest rate differential affects the exchange rate, there appears to be some evidence of more negative relationships at the shorter time scales and more positive relationships at the longer time scales.
\end{abstract}

Key Words: exchange rate, interest rate differential, Granger causality, wavelet analysis, uncovered interest rate parity

JEL Classification: C32, E44, F31, F42 
1.

\section{Introduction}

The relationships between the economic variables we are considering have been investigated in international economics within the framework of tying exchange rates to various macroeconomic fundamental variables including interest rates, but also frequently including relative money supplies and domestic and foreign outputs (Dornbusch, 1976; Frenkel, 1976; Bilson, 1978; Frenkel, 1979; Engle and West, 2005 among others). The theoretical relationship between the spot exchange rate (defined in this paper as the domestic-currency price of foreign currency) and the interest rate differential (the domestic interest rate minus the foreign interest rate) is typically considered to be negative in the short run when product prices are sticky and positive in the long-run when they are not. The short-run negative relationship arises from the intuition that, all else equal, an increase in the home-country interest rate relative to the foreign one will induce financial capital flows to the home country, which creates pressure for the home country's currency to appreciate. The long-run positive relationship can be explained by the intuition that the home-country interest rate increasing relative to the foreign one frequently reflects an increase in the conditions for higher inflation in the home country relative to the foreign one, which also creates pressure for the home country's currency to depreciate. A positive relationship in the long-run and even in the short-run may be explained by depreciation of the home-country currency leading to an increase in the home country's trade balance and a decrease in the foreign trade balance, which induces the domestic interest rate to rise and the foreign interest rate to fall.

The contemporaneous relationship at different time scales between the spot exchange rate and interest rate differential was studied by using wavelets and simple regression in a paper by Hacker, Kim and Månsson (2009). However, by just investigating the contemporaneous relationship between these variables using simple regression, that paper had its results subjected to several problems such as autocorrelation and explanatory-variable endogeneity. By using dynamic models instead and by using Granger causality one can diminish these problems (again using wavelet-decomposed data). Also, by considering Granger causality in either direction between the variables of interest, one can gain further insights on how they are related.

In investigating the relationship between exchange rates and interest rate differentials, wavelet analysis is used in this paper. Wavelet analysis has become increasingly popular for analyzing economic time series due to its advantages that one can decompose a time series into different time scales so the relationship between variables can be analyzed at the short run, intermediate run and up to the long run. This has been done by for example Ramsey \& Lampart (1998) to investigate the permanent income hypotheses and in Almasri \& Shukur (2003) to examine the causality in a Granger sense between government spending and revenue. In this paper we explore the Granger-causal relationships between the spot exchange rate and the cross-country difference in the rate of interest, with wavelet decomposition utilized to consider these relationships at various time scales. Impulse responses associated with the utilized time scales are also investigated to consider the sign of the effect of one variable on the other over time.

In the wavelet decomposition of this paper, a multiresolutionary analysis (MRA) for a maximal overlap discrete wavelet transform (MODWT) is used to filter the data. Subsequently, to test for Granger causality a method developed by Månsson \& Shukur (2009) is used. According to that method the causality testing is performed by applying an LM test 
with White's heteroscedasticity consistent covariance matrix (HCCME). This method is chosen since a characteristic of the investigated variables is that the variance of each studied time series is non-constant and follows an autoregressive conditional heteroscedasticity $(\mathrm{ARCH})$ process or generalized autoregressive conditional heteroscedasticity (GARCH) process. Finally to consider the sign of the relationship between the variables associated with the causal effect we use impulse response functions.

The data used to test for Granger causality are monthly spot exchange rates for six currencies (U.S dollar, Japanese yen, euro, pound sterling, Norwegian krone and Swiss franc) against the Swedish krona along with the three-month Treasury bill interest rates for the associated countries. By performing this investigation for several pairs of countries we can consider the robustness of the empirical relationships between the variables of interest. The choice to focus on Sweden versus other countries is based on taking advantage of Sweden's smallcountry situation, a characteristic utilized in many open macroeconomic models to reduce some feedback.

The paper is organized as follows. In the next section the economic theory and previous research in the area is studied. In section 3 the theoretical foundations of wavelet filtering is explained, then in section 4 the data is described along with some example wavelet decomposition. In section 5 a description is provided for the methodology used when testing for Granger causality and for generating impulse responses. Then in section 6 the results from the Granger causality tests and impulse responses are described and in section 7 the conclusions drawn are summarized.

\section{Economic theory and previous research}

The introduction briefly covered the intuition behind the short-run and long-run relationships between the exchange rate and the interest rate differential. In this section we present more in detail five open-macroeconomic models which include a distinctive short-run element. These models are 1) a simple Keynesian model with an exogenous exchange rate change, 2) the floating exchange-rate version of the Mundell-Fleming model, 3) the Dornbusch (overshooting) model, 4) the portfolio-balance, and 5) Redux model. By discussing these models we hope to illuminate some issues on causality between our variables of interest when considering the initial reactions to an economic shock - an increase in the money supply of the home country as an example - and subsequent adjustments. We also briefly discuss a couple of long-run models to round-out the discussion, and present some previous empirical research in the area.

In our discussion we will often discuss how the domestic interest rate moves and assert without explanation that the interest rate differential moves in the same direction. The reason is that in these cases we can say that the foreign interest rate is either constant (due to a small country assumption) or that the foreign interest rate is moving in the opposite direction due to a symmetrically opposite logic. Also it is important to recognize that our definition of the exchange rate as the domestic-currency price of foreign currency has the implication that a rise in that exchange rate is synonymous with depreciation of the home currency.

First we consider how the interest rate differential and the exchange rate could be related through an exogenous change in the exchange rate. An increase in a country's exchange rate due to exogenous real exchange rate movement (due to changes relative supply and relative demands for the products of various countries) leads to an increase in that country's trade 
balance. If one considers the standard IS-LM framework, that increase in the trade balance in turn drives up that country's interest rate due to the increase in aggregate demand for its products. This channel is referred to as Keynesian here due to its focus on aggregate demand. This phenomenon works as presented in the sticky price world typically assumed in the short run for Keynesian models. In the long-run, assuming the country had full employment to begin with the increase in aggregate demand drives output to be above the full-employment level, which induces price increases that cause real money supply to fall and interest rates to rise further in the long run. Thus both in the short run an in the long run, this model indicates a positive causal relationship from the exchange rate to the interest rate differential.

In the Mundell-Flemming (M-F) model (as in Mundell, 1962, Fleming, 1962, and in countless textbooks), the effect of an initial policy action and its sequential adjustment in this model depends on the degree of capital mobility. In case of high capital mobility, ${ }^{1}$ the effect of monetary expansion or fiscal contraction in the home country is a decrease of the interest rate at home, given that the home country is small and foreign variables are exogenously taken. The decrease in the interest rate of the home country leads to an incipient deficit in the balance of payments at the original exchange rate due to a potentially massive capital outflow from the home country. Therefore, there is an excess demand for foreign currency at the original exchange rate, so the exchange rate of the home country depreciates. That depreciation leads to an increase in the trade balance for the home country, which in turn means that aggregate demand in the home country increases so the home-country interest rate increases and the capital account does not drop as much as it would otherwise. Overall, the home-country interest rate ends up lower than before the monetary expansion, and to meet the requirement that the balance of payments must be zero at all times, the exchange rate must rise sufficiently such that that increase in the trade balance totally offsets the overall drop in the capital account (or financial account, in more modern terminology). In this model we see that in the short-run a negative causal relationship from the interest rate differential to the exchange rate is apparent - the interest rate falls and because of that the exchange rate rises. At the time scale we see also see causality in the other direction with an opposite sign in the relationship: the rise in the exchange rate causes the trade balance to increase, resulting in a rise in the exchange rate. ${ }^{2}$

The Dornbusch overshooting model, originally formulated by Rudiger Dornbusch (1976), includes an explicit treatment of expectations of exchange rate changes, the lack of which is a serious problem with the Mundell-Fleming model, and, unlike the latter model, demonstrates what happens between the sticky-price short-run and the flexible price long-run. In the Dornbusch overshooting model, the two markets-the financial market and the goods marketare allowed to have different adjustment speeds. The consequence of allowing in these two markets is that financial market has to overadjust to disturbances, so that the price-stickiness in the goods market can be compensated in the short-run. In this model, monetary expansion

\footnotetext{
${ }^{1}$ We confine the explanations to the case of high capital mobility (flatter balance of payment (BP) schedule than the money market equilibrium (LM) schedule) since it suits better as a theoretical base for studying the spot exchange rate of Swedish kronor against bigger economies and their interest rate differential. The effects of the policy responses in the M-F model, however, can also be studied in other cases: no-capital mobility (vertical BP schedule), some capital mobility (steeper BP schedule than the LM schedule), and perfect capital mobility (horizontal BP schedule). The slope of the upward-sloping BP schedule represents the degree of the capital mobility; the fatter, the more mobile the capital is.

${ }^{2}$ The signs of these causal relationships in the short-run do not change based upon whether the initial shock is contractionary or expansionary.
} 
by the home country causes the interest rate to drop, which in turn results in the exchange rate rising immediately to maintain UIP. The UIP condition is

$$
i-i^{*}=\frac{E^{e}}{E}-1
$$

where $i$ is the domestic interest rate, $i^{*}$ is the foreign interest rate, $E$ is the spot exchange rate, and $E^{e}$ is the expected future exchange rate (the long-run exchange rate in this model). Keeping $i^{*}$ and $E^{e}$ constant, a drop in $i$ needs to be offset by a rise in $E$ to maintain the equality. The monetary expansion also makes the expectation of the future exchange rate increase, since prices will rise which in turn put pressure on the exchange rate to be higher ultimately to maintain purchasing power parity. The consequence of the higher $E^{e}$ is even more pressure for $E$ to rise to maintain UIP, resulting in $E$ overshooting its level in the longrun. Between the short-run and the long-run, prices rise, which results in $i$ rising and (again to maintain UIP) $E$ falling. As in the Mundell-Fleming model, there appears a negative causal relationship from the interest rate to the exchange rate in the short run in the Dornbusch overshooting model. However, between the short-run and the long-run, this negative causal effect of $i$ on $E$ continues, driven always by UIP.

The portfolio balance model, brought to prominence in Branson (1983), Branson and Halttunen (1979) and Branson, Halttunen, and Masson (1979), allows for investors' concerns about the riskiness of the assets in which they are invested and considers the slow adjustment of goods prices as in the Dornbusch model. Similar to the Mundell-Fleming model, a reduction in the return on assets in the home country (due to a monetary expansion, say) will initially result in capital flows out of that country, but unlike Mundell-Fleming, those capital flows stop once investors have adjusted their portfolio shares to make the optimal trade-offs between risk and return. This situation again leads to an depreciation of the home country's currency - the same reaction we saw in Mundell-Fleming and through the UIP condition in the Dornbusch model. ${ }^{3}$ The decrease in the interest rate in the home country due to a money supply increase, thus, leads to an excess demand for money and the excess supply of domestic bonds while it creates an excess demand for foreign denominated asset in a foreign currency. This process makes the exchange rate go up (i.e. domestic currency depreciation), which allows us to draw a negative causal relationship from the interest rate to the exchange rate in the short run, as in the Dornbush and Mundell-Fleming models.

After the initial depreciation in the portfolio balance model, the home country collects foreign assets due to the depreciation-induced current account surplus (assuming it started with a current account equal to zero). Between the short-run and the long-run in this model, two adjustments are occurring. First, the home-country's goods prices are rising, reducing the competiveness it gained through the depreciation. Second, the home country's exchange rate appreciates since the home-country investors value foreign assets less considering they collected a lot of them already through the short-run current account surplus. Also the exchange rate appreciates sufficiently to support a long-run home-country current account deficit funded by interest collected on the earlier collected foreign assets from the short-run current account surplus. As in the Dornbusch model, there is overshooting of the exchange

\footnotetext{
${ }^{3}$ Note that in the portfolio balance model, UIP is inoperative due to the risk premium which is pervasive in the financial markets, but the intuition behind the relationship between the two variables is not different from UIP in the sense that investors in the financial markets choose to adjust their investment toward the asset with a higher return.
} 
rate, but the adjustment process does not include a change in the interest rate, so no causal relationship between the exchange rate and the interest rate is supported after the short run.

The Redux model is a general equilibrium exchange-rate determination model dealing with two countries with the characteristics of monopolistically competitive industries, sticky prices, and an intertemporal approach to the current account balance, which was developed by the initial work of Obstfeld and Rogoff (1995). There is no causal relationship between the exchange rate and the interest rate is supported in its earlier form where uncovered interest rate parity is holding but monetary shocks simply cause nominal interest rates to change by the same amount in both countries so no expected depreciation or appreciation after that change is created. However, within the appendix of Obstfeld and Rogoff (1995) paper, an alternative small open economy model with nontraded consumption goods is presented, and that model does have the possibility that a money-supply increase Granger causes an exchange-rate to overshoot. Lane (2001) notes that that overshooting is associated with a lowered short-run nominal interest rate. An extension of the Redux model is made by Betts and Devereux (2000) by including pricing to market through local currency pricing, and found that under such circumstances a monetary expansion could lead to the interest rate differential decreasing along with exchange rate overshooting (a static version of this model was provided in Betts and Devereux, 1996).

What one sees from these exchange-rate determination models is the repeated negative effect of the interest rate differential on the exchange rate in the short run. In the adjustment process the Dornbusch model continues this same effect through UIP. The situation becomes less clear however when we consider lagged relationships - as is typical with Granger causality models. The initial short-run drop in the interest rate should be followed by adjustmentperiod increases in the exchange rate in the Mundell-Fleming model (leading potentially to negative Granger causality from the interest rate differential to the exchange rate) and by adjustment-period decreases in the exchange rate in the Dornbusch and portfolio balance model (leading potentially to positive Granger causality from the exchange rate to the interest rate differential).

To complete our discussion on exchange-rate determination models, we present two additional ways of having a positive relationship between the two variables. First, we could simply consider an exogenous increase in interest rate decreasing money demand, resulting in higher prices which in turn lead to a higher exchange rate through purchasing power parity. Second, we could consider an increase in the home interest rate reflecting an increase in inflationary expectations at home (the Fisher (1930) effect), which is often accompanied by higher actual inflation there and that higher actual inflation leads to an increasing exchange rate, again through purchasing power parity. The first channel indicates a positive casual effect of the interest rate differential on the exchange rate, whereas the second simply indicates a positive relationship between the two variables caused by the common factor of inflation. These two channels are distinctly monetarist, due to the focus on the money market being the source of exchange rate changes. Table 1 summarizes the above discussion with both the short-run and long-run models. 
Table 1: Causal relationships suggested by various exchange rate determination models

\begin{tabular}{|c|c|c|c|c|}
\hline & Short-run & $\begin{array}{l}\text { Adjustment } \\
\text { Process }\end{array}$ & $\begin{array}{l}\text { Short run } \\
\text { to } \\
\text { Adjustment }\end{array}$ & Long run \\
\hline $\begin{array}{l}\text { Monetarist: } \\
\text { Money Demand Effect }\end{array}$ & & & & $i-i^{*} \stackrel{+}{\rightarrow} E$ \\
\hline $\begin{array}{l}\text { Monetarist: } \\
\text { Fisher Effect }\end{array}$ & & & & $\begin{array}{c}i-i^{*} \text { and } E \\
\text { positively related }\end{array}$ \\
\hline $\begin{array}{l}\text { Keynesian: } \\
\text { Exogenous Exchange } \\
\text { Rate Change }\end{array}$ & $E \stackrel{+}{\rightarrow} i-i *$ & & & $E \stackrel{+}{\rightarrow} i-i^{*}$ \\
\hline Mundell-Fleming & $\begin{array}{l}i-i^{*} \underset{\rightarrow}{\rightarrow} E \\
\stackrel{+}{\rightarrow} i-i^{*}\end{array}$ & & & \\
\hline Dornbusch & $i-i * \stackrel{-}{\rightarrow} E$ & $i-i^{*} \stackrel{-}{\rightarrow} E$ & $i-i * \stackrel{+}{\rightarrow} E$ & \\
\hline Portfolio Balance & $i-i^{*} \stackrel{-}{\rightarrow} E$ & $\begin{array}{l}\text { E reverses } \\
\text { direction of } \\
\text { movement } \\
\text { found in the } \\
\text { short-run }\end{array}$ & $i-i^{*} \stackrel{+}{\rightarrow} E$ & $i-i^{*} \stackrel{-}{\rightarrow} E$ \\
\hline Redux model & $i-i^{*} \stackrel{-}{\rightarrow} E$ & $\begin{array}{r}\text { No cau } \\
i-i^{*} \stackrel{-}{\rightarrow} E \\
\end{array}$ & $\begin{array}{r}\text { relationship } \\
\qquad i-i * \stackrel{+}{\rightarrow} E\end{array}$ & \\
\hline
\end{tabular}

Each arrow indicates the direction of the causal relationship while the sign above the arrow represents the sign of the causal relationship.

In order to deal with the different time-horizon issue, previous studies have been using a vector autoregression system where they put a long-run restrictions (monetary neutrality) following the Blanchard-Quah identification strategy. By identifying permanent and transit component of the nominal and real exchange rate, sources of the fluctuations in the exchange rates have been empirically estimated (Lastrapes, 1992;. Clarida and Gali (1994)). Clarida and Gali (1994) have shown that lagged interest differentials did not Granger cause subsequent real exchange rate changes. Cheng (1999) examined the causality between the dollar and the yen in a multivariate framework by using Hsiao's version of the Granger causality test (Hsiao, 1981) in which all variables are required to be stationary. The test result showed that causality from interest rates to exchange rates is found in the short run. Engels and West (2005) used a conventional class of asset-pricing models in which an asset price (exchange rate) is expressed as a present discounted sum of a linear combination of observable fundamentals and unobservable shocks. In the bivariate Granger causality tests between bilateral U.S. exchange rates versus other six G7 member countries with different measures of the changes in fundamental variables, they found modest evidence that exchange rates helps to predict fundamental economic variables such as money supply, output and interest rate. However, they only found some weak evidence that the fundamental variables Granger causes the spot exchange rate. 


\section{Wavelet analysis}

In general the wavelet transformation restructures data using an orthonormal basis in the space of square integrable functions. The orthonormal basis used for wavelets is given by

$$
\psi_{j k}(x)=2^{j / 2} \psi\left(2^{j} x-k\right),
$$

for various $j, k$, and $x$, where $j$ and $k$ respectively dilate and translate the mother wavelet function $\Psi(z), z=2^{j} x-k$. The mother wavelet function in this paper is the Haar function,

$\psi=\left\{\begin{array}{c}1 \text { if } z[0,0.5) \\ -1 \text { if } z[0.5,1) \\ 0 \text { otherwise }\end{array}\right.$

A greater $j$ value squeezes the $x$ interval with nonzero values, whereas a higher $k$ shifts that interval rightwards. For a data vector $y$ with $N$ observations, where $N$ equals $2^{n}$ for some integer $n$, the discrete wavelet transformation (DWT) of that data vector $y$ associated with equation (4) is generally given by

$$
f(x)=c_{0} \phi(x)+\sum_{j=0}^{n-1} \sum_{k=0}^{2^{j}-1} w_{j k} \psi_{j k}(x)
$$

where the constants $c_{0}$ and $w_{j k}$ are known as the wavelet coefficients, the function $\phi(x)$ is known as the father wavelet or the scaling filter, and $x$ is defined between 0 and 1 . In our specific case, using the Haar mother wavelet, the associated father wavelet is $\phi(x)=1$. The scale level, $\lambda$, which we will interpret intuitively shortly, is given as $\lambda=n+1-j$, so with appropriate reindexing and when using the Haar wavelet we may rewrite equation (6) as

$$
f(x)=c_{0}+\sum_{\lambda=1}^{n} \sum_{k=0}^{n-m} c_{\lambda k} \psi(\lambda, k, x)
$$

where $c_{0}$ is the overall mean of the data in $y, m=\log _{2} 2^{\lambda}, c_{\lambda k}=w_{n+1-\lambda, k}$, and $\psi(\lambda, k, x)=\psi_{n+1-}$ $\lambda, k(x)$. With $y$ containing data from a time series, the wavelet coefficients $c_{\lambda k}$ reflect patterns in that data indicating movements occurring every $2^{\lambda-1}$ periods. Therefore the wavelet coefficients with $\lambda=1$ reflect changes happening after one period, those with $\lambda=2$ reflect changes happening after two periods, and those with $\lambda=5$ reflect changes happening after 16 periods.

The DWT using the Haar wavelet simply uses averages over contiguous pairs of values from the averages (or original data in the first step) of the previous scale level with no value used more than once in different averages, but like any DWT it suffers from being sensitive to the point at which one starts the averaging, being limited to observation sizes that are an element of the didactic series $\left(N=2^{n}\right.$ for some integer $\left.n\right)$, and having fewer distinct values from the averages as the scale increases (the number is halved for each successively higher scale level). Due to the limited number of observations in our data set, the last problem is a severe one for the research in this paper, so instead of DWT we use the alternative maximum overlap discrete wavelet decomposition (MODWT). Unlike DWT, MODWT uses at every scale level moving averages, and as a consequence avoids the problems noted above with 
DWT. ${ }^{4}$ However, by using moving averages, the MODWT loses the orthogonality which is characteristic of DWT. To maintain consistency in the transformation of the data series using MODWT, the data is considered as a circular loop, with the observation following the last one simply being the first observation. This "trick" however makes the resulting differences and averages for the endpoint data at the lower scales especially sensitive to the distance between the last and first observation, so the affected endpoint differences and averages are dropped from the subsequent analysis at the lower scales.

The MRA for MODWT generates for every scale level $\lambda$ a smooth series containing the means at that scale, and a detail series containing the differences between the previous lowerlevel's smooth series and the smooth series at the current level (this terminology was first used by Percival \& Mjofeld, 1997).

Mallat (1989) provided a quick method for calculating the wavelet details and smooth which can easily be described using matrix calculations. To illustrate the method we have to define $\mathbf{y}$ which is a vector consisting of time series data (ordered accordingly) with the associated level- $\lambda$ detail smooth and detail series being $\mathbf{s}_{\lambda}$ and $\mathbf{d}_{\lambda}$ Then we have to define the following matrices:

$$
\mathbf{W}_{1}=\left[\begin{array}{cccccc}
\frac{1}{2} & 0 & \cdots & 0 & 0 & -\frac{1}{2} \\
-\frac{1}{2} & \frac{1}{2} & 0 & \cdots & 0 & 0 \\
0 & 0 & 0 & \ddots & 0 & 0 \\
0 & 0 & 0 & 0 & -\frac{1}{2} & \frac{1}{2}
\end{array}\right] ; \mathbf{V}_{\lambda}=\left[\begin{array}{cccccc}
\frac{1}{2^{\lambda}} & 0 & \cdots & 0 & 0 & \frac{1}{2^{\lambda}} \\
\frac{1}{2^{\lambda}} & \frac{1}{2^{\lambda}} & 0 & \cdots & 0 & 0 \\
0 & 0 & 0 & \ddots & 0 & 0 \\
0 & 0 & 0 & 0 & \frac{1}{2^{\lambda}} & \frac{1}{2^{\lambda}}
\end{array}\right]
$$

where $\mathbf{W}_{\mathbf{1}}$ is used to calculate the wavelet details at level 1 and $\mathbf{V}_{\mathbf{j}}$ is used to obtain the transform matrices when the level is greater than 1.

The first step in the algorithm is to calculate the wavelet details at level 1 using the formula $\mathbf{d}_{1}=\mathbf{W}_{1}^{\mathrm{T}} \mathbf{W}_{1} \mathbf{y}$. The transform matrix of level two equals $\mathbf{W}_{2}=\mathbf{W}_{1} \mathbf{V}_{1}+\tau^{1}\left(\mathbf{W}_{1} \mathbf{V}_{1}\right)$ where $\tau$ circularly shifts the values one step to the left and so the first row becomes the last row of the matrix. Then the wavelet details at level two equals $\mathbf{d}_{2}=\mathbf{W}_{2}^{\mathbf{T}} \mathbf{W}_{2} \mathbf{y}$. At level three the transform matrix equals $\mathbf{W}_{3}=\mathbf{W} \mathbf{V}_{2}+\tau^{1}\left(\mathbf{W} \mathbf{V}_{2}\right)+\tau^{2}\left(\mathbf{W} \mathbf{V}_{2}\right)+\tau^{3}\left(\mathbf{W} \mathbf{V}_{2}\right)$ where $\tau^{i}$ ciruclarly shifts the values of the matrix $i$ steps to the left. Thus the wavelet details at level 3 equals

\footnotetext{
${ }^{4}$ With MODWT we can define $n$ as being $\log _{2} N$ rounded up to the nearest integer.
} 
$\mathbf{d}_{3}=\mathbf{W}_{3}^{\mathrm{T}} \mathbf{W}_{3} \mathbf{y}$. Then the wavelet smooth at level three can be calculated as

$\mathbf{s}_{3}=\operatorname{abs}\left(\mathbf{W}_{3}^{\mathbf{T}} \mathbf{W}_{3}\right) \mathbf{y}$.

Since the MRA is an additative decomposition we get the original series by summing up the level-1 to level- $\Lambda$ detail series, where $\Lambda$ is the highest considered scale level, and adding the result to the level- $\Lambda$ smooth series,

$$
\mathbf{y}=\mathbf{s}_{\Lambda}+\sum_{\lambda=1}^{\Lambda} \mathbf{d}_{\lambda}
$$

The variable's long-term trend at the scale level of $\Lambda$ is given by $\mathbf{s}_{\boldsymbol{\Lambda}}$, which contains the nonstationary components of the original series if any exist. The original series' decomposition at various time scales is given by the detail series $\mathbf{d}_{1}$ to $\mathbf{d}_{\Lambda}$.

\section{Data and wavelet decomposition of that data}

The empirical analysis in this paper is based on two data sources: the foreign exchange (FX) history provided by the OANDA corporation and the Ecowin database which gathered the data from Reuters and central banks (Federal Reserve, The Bank of England). The monthly and quarterly spot exchange rates are the values of various currencies against the Swedish Krona (SEK), specifically the values of five major currencies (the U.S dollar (USD), the Japanese yen (JPY), the euro (EUR), the British pound sterling (GBP) and the Swiss Franc $(\mathrm{CHF})$ ) and the value of one minor currency (the Norwegian krone, NOK). All of the exchange rates are averages of ask prices. The interest rates used in this study are yields from the three-month T-bill since its return is simply the three-month interest rate. Both spot exchange rates and interest rates are end-of-the month observations. The sample periods cover only the floating period of the exchange rate, hence it varies for each currency depending on the availability of data since the floating exchange rate regime was adopted. The sample period of the Swedish Krona starts from January, 1993; for the euro January, 2000; and for the Swiss franc May, 2000. The sampled periods are covered up to May, 2009. Following the presentation style of the earlier section, $E$ denotes the spot exchange rate and $\ln E$ is its logarithm, notations which are shown in the regression and figures. The nominal interest rate differential is defined as the difference between the log of one plus the Swedish rate of interest and the log of one plus the foreign rate of interest. ${ }^{5}$ Henceforth, idiff will be simply referred to as the interest rate differential (including in the regression and figures) although it is not the same $i-i^{*}$ which was shown in the earlier section.

Figures 2 and 3 represent the raw data and the wavelet filtered data of the spot exchange rate and the interest rate differential between Sweden and the euro area as an example. ${ }^{6}$ The graph on the left-hand side on the top row of each figure shows the raw data series, while other seven graphs are the wavelet filtered data which are broken out into six different scale levels. The lower-case letters, $d$ and $s$, on the vertical axis of the graphs of wavelet filtered data

\footnotetext{
${ }^{5}$ Formally the uncovered interest rate parity condition in equation (1) is just an approximation, but it is often used in theoretical works. The exact version is equation (1) is $i=\left(E^{e} / E\right)\left(1+i^{*}\right)-1$ or equivalently

$1+i=\left(E^{e} / E\right)\left(1+i^{*}\right)$. Taking logs on both sides and rearranging we get $\ln E=\ln E^{e}-\left(\ln (1+i)-\ln \left(1+i^{*}\right)\right)$.

${ }^{6}$ Since it would take too much space to present all time series only one is presented. Graphs over all wavelet filtered time series are, however, available from the authors upon request.
} 
denote wavelet detail and wavelet smooth, respectively. The numbers appended to notations of the wavelet details and smooth represent time scales. Compared to the notations in the earlier section, slight changes in the notations of the time scales have been made in the graphical representations of the data due to the convention of our software. In empirical presentations here and later, we follow the convention of the software, and have the level of a smooth or detail appended to $s$ or $d$ not subscripted and removed the italics on $s$ and $d$, e.g. $\mathrm{s} 1 \equiv s_{1}$ and $\mathrm{d} 2 \equiv d_{2}$. Due to the construction of the scale levels, $\mathrm{d} 1$ is associated with a oneperiod movement frequency (changes can occur between consecutive periods), $\mathrm{d} 2$ with a twoperiod movement frequency (changes occurring every two periods), $\mathrm{d} 3$ with a four-period movement frequency, d4 with an eight-period movement frequency, d5 with sixteen-period movement frequency, and $\mathrm{d} 6$ with a thirty-two period movement frequency. The wavelet scale refers to these movement frequencies. The non-stationary components (trend) of the time series will be found in the wavelet smooth, s6. In both figures 2 and 3, the variations of the detail series at different time-scales tend to differ in terms of the elapsed time of oscillations. That is, the longer the time scales are, the longer the oscillations of the time series become thereby making the time between consecutive peaks and between consecutive troughs get longer. As is noticeable in Figure 3, the wavelet smooth (s6) illustrates that the peak of the smoothed interest rate differential was around the year 2002, corresponding to what is seen with the interest rate differential from the original time series.
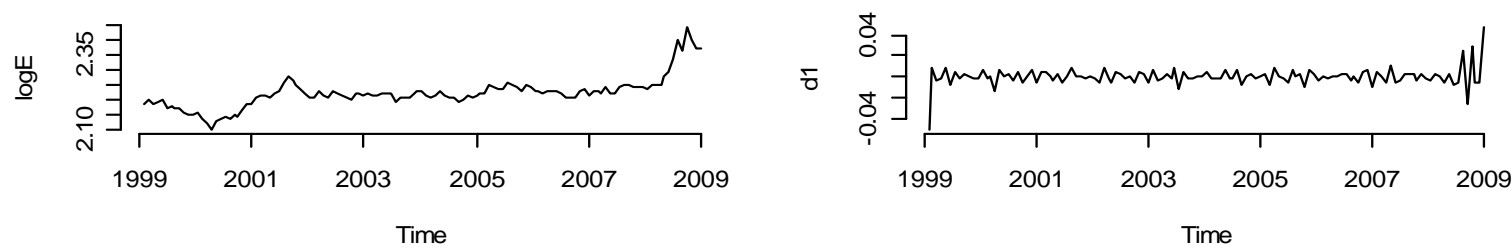

$\approx$

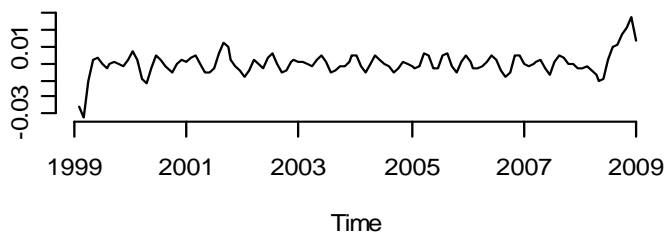

宕

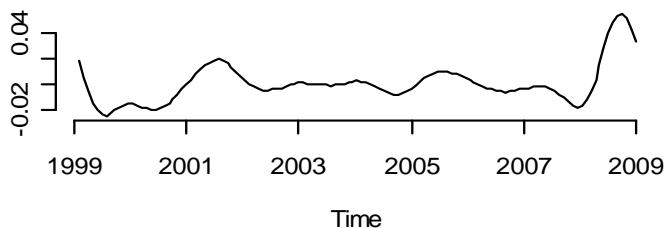

$\stackrel{0}{0}$

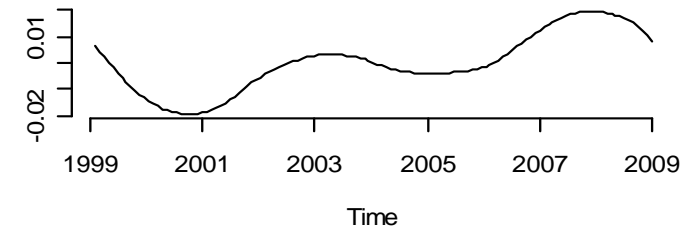

m

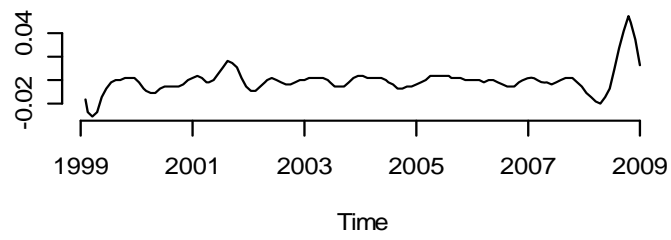

농

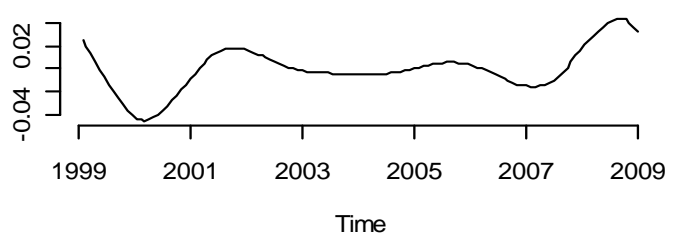

i

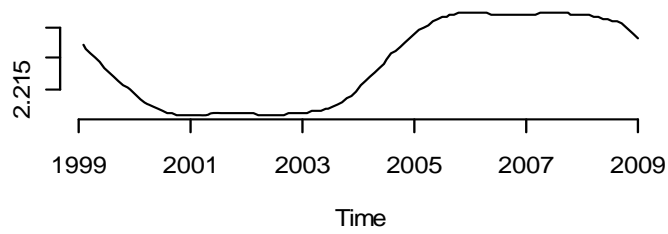


Figure 2. Time series plots of data for the monthly spot exchange rate (SEK/EUR in log scale)
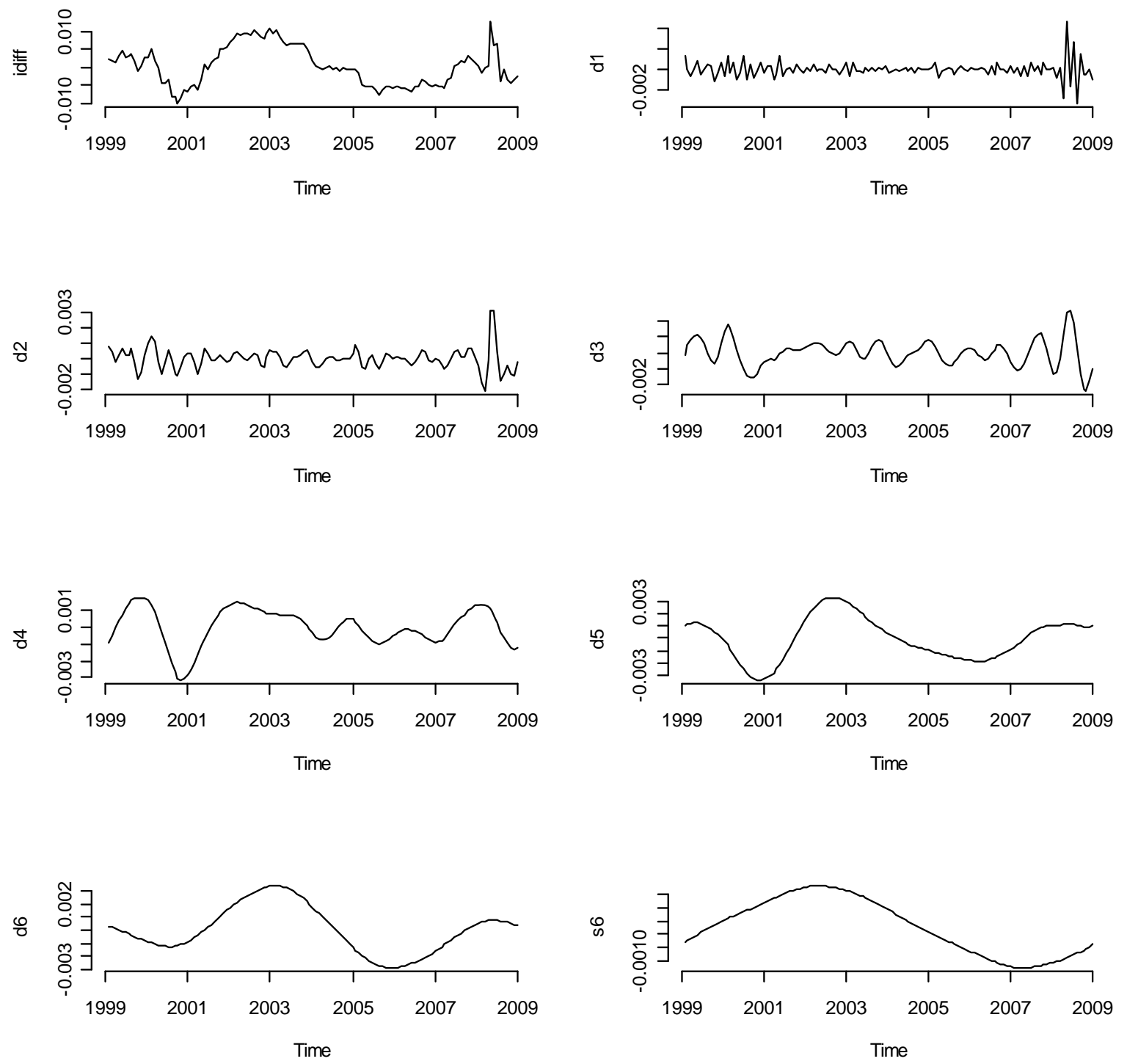

Figure 3. Time series plots of data for the monthly nominal interest differential between Sweden and the EURO zone

\section{Estimation and testing methodologies}

For each country pair and at each wavelet scale we test for Granger causality in both directions between the interest rate differential and the exchange rate. To consider the sign of the relationship between the variables indicated by the vector autoregressive (VAR) model used in the Granger causality tests, we also investigate impulse responses in both directions. In this section we present the estimation of the VAR model and the subsequent Granger causality testing. We also discuss how we use impulse response functions to provide further information on the sign of the relationship between the variables under investigation. 
For our analysis we use for a pair of countries the detail series at the same scale for the log exchange rate and the log interest rate differential, the time $t$ values of which are $d_{t}^{E}$ and $d_{t}^{i}$ respectively. We have $T$ observations in these series after removing some endpoint observations which are strongly affected by the wavelet decomposition's circular treatment of the data order. Letting

$$
y_{t} \equiv\left[\begin{array}{c}
d_{t}^{E} \\
d_{t}^{i-i^{*}}
\end{array}\right]
$$

we proceed to estimate the vector autoregressive model of order $K$, $\operatorname{VAR}(K)$, as shown below:

$$
\left[\begin{array}{c}
d_{t}^{E} \\
d_{t}^{i-i^{*}}
\end{array}\right]=\left[\begin{array}{l}
\beta_{01} \\
\beta_{02}
\end{array}\right]+\left[\begin{array}{ll}
\beta_{11}^{(1)} & \beta_{12}^{(1)} \\
\beta_{21}^{(1)} & \beta_{22}^{(1)}
\end{array}\right]\left[\begin{array}{c}
d_{t-1}^{E} \\
d_{t-1}^{i-i^{*}}
\end{array}\right]+\left[\begin{array}{ll}
\beta_{11}^{(2)} & \beta_{12}^{(2)} \\
\beta_{21}^{(2)} & \beta_{22}^{(2)}
\end{array}\right]\left[\begin{array}{c}
d_{t-2}^{E} \\
d_{t-2}^{i-i^{*}}
\end{array}\right]+\cdots+\left[\begin{array}{cc}
\beta_{11}^{(K)} & \beta_{12}^{(K)} \\
\beta_{21}^{(K)} & \beta_{22}^{(K)}
\end{array}\right]\left[\begin{array}{c}
d_{t-K}^{E} \\
d_{t-K}^{i-i^{*}}
\end{array}\right]+\left[\begin{array}{l}
u_{1 t} \\
u_{2 t}
\end{array}\right]
$$

where the various $\beta$ parameters are constants and $\left[u_{1 t} u_{2 t}\right]^{\prime}$ is the error vector at time $t$. The number of lags of the regression models, $K$, is decided by using the Schwarz (1978) information criteria (SIC), the Hannan \& Quinn (1979) criteria (HQ) and Akaike (1971) information criteria (AIC), along with testing for autocorrelation using the Rao F-test developed by Edgerton \& Shukur (1999). In the first step we determine the order of the VAR process by using SIC, and test for autocorrelation. If any significant autocorrelation is detected, the lag suggested by HQ is used and autocorrelation is tested for again. If any significant autocorrelation is remaining when HQ is used the AIC criteria is used.

Further diagnostic checking with the VAR model is performed. If the AIC-suggested lag is used, additional testing for autocorrelation is performed. To check for GARCH effects and non-normality the Breusch-Godfrey LM-test for GARCH effects and the Jarque-Bera (1987) test for non-normality are used. The misspecification tests indicate GARCH effects and nonnormality in almost every case.

According to Granger \& Newbold (1986) one can test for Granger causality by evaluating a zero restriction in each of the single linear equations in the VAR model:

$$
\begin{aligned}
& d_{t}^{E}=\beta_{01}+\sum_{k=1}^{K} \beta_{11}^{(k)} \ln d_{t-i}^{E}+\sum_{k=1}^{K} \beta_{12}^{(k)} d_{t-k}^{i-i^{*}}+u_{1 t} \\
& d_{t}^{i-i^{*}}=\beta_{21}+\sum_{k=1}^{K} \beta_{21}^{(k)} \ln d_{t-k}^{E}+\sum_{k=1}^{K} \beta_{22}^{(k)} d_{t-k}^{i-i^{*}}+u_{2 t}
\end{aligned}
$$

To test whether the interest rate differential Granger causes the spot exchange rate one should test the hypothesis that all of the $\beta_{12}^{(k)}$ parameters are zero can be statistically rejected, and to test whether the interest rate differential Granger causes the spot exchange rate one should test the hypothesis that all of the $\beta_{21}^{(k)}$ parameters are zero can be statistically rejected. In matrix notation, this can be done be evaluating the following restriction: 
$H_{0}: \mathbf{R} \boldsymbol{\beta}=\mathbf{0}$

where $\boldsymbol{\beta}$ is a $(2 K+1) \times 1$ vector containing all of the coefficient parameters in equation (9) or (10), $\mathbf{R}$ is a fixed $K \times(2 K+1)$ matrix with each row consisting of zeros except for a one for the element corresponding to an element in $\boldsymbol{\beta}$ being restricted to zero, and $\mathbf{0}$ is a $K \times 1$ vector. Each row in $\mathbf{R}$ corresponds to restricting one of the $\beta_{12}^{(k)}$ parameters if equation (9) is being dealt with, or one of the $\beta_{21}^{(k)}$ parameters if equation (10) is being dealt with.

Since we frequently found GARCH effects present in our diagnostic checking, we use the singlewise LM test with White's HCCME, which is shown in Månsson \& Shukur (2009) to have an unbiased size in the presence of GARCH effects. The LM test in our case can be expressed as:

$$
L M=T(R \hat{\beta})^{\prime}\left(R \hat{\Sigma}_{r} R^{\prime}\right)^{-1}(R \hat{\beta})
$$

where

$$
\hat{\Sigma}_{r}=T\left(\mathbf{X}^{\prime} \mathbf{X}\right)^{-1}\left[\mathbf{X}^{\prime} \hat{\mathbf{\Sigma}} \mathbf{X}\right]\left(\mathbf{X}^{\prime} \mathbf{X}\right)^{-1},
$$

with $\mathbf{X}$ being the matrix of explanatory variables for equations (9) and (10) and with

$$
\hat{\boldsymbol{\Sigma}}=\operatorname{diag}\left(\hat{u}_{1}^{2}, \ldots, \hat{u}_{t}^{2}\right) \text {. }
$$

This test follows an asymptotic $\chi^{2}(K)$ distribution. The commonly used estimator of the restricted covariance matrix is equal to $\hat{\Sigma}_{r}=\hat{\sigma}_{r}^{2}\left(\mathbf{X}^{\prime} \mathbf{X}\right)^{-1}$ where $\hat{\sigma}_{r}^{2}$ is the estimated variance of the model restricted by null hypothesis being tested. This estimator is replaced by the above estimator of $\hat{\Sigma}_{r}$ when using the LM test with White's HCCME since we cannot assume that the error term is homoscedastic due to the GARCH effects.

Since Granger causality tests do not indicate anything about the sign of causal relationship found, and since such a sign is difficult to determine unless only one lag is used, we resort to impulse response functions to provide information on what sign is likely associated with any Granger causality found. To investigate the sign of the relationship between exchange rates and interest rate differentials, impulse response functions are generated using our unconstrained estimated VAR models, where the covariance matrix is orthogonalized using the Cholesky decomposition. When the impulse response function is estimated we report the sign of the response of the investigated causal variable to the investigated caused variable at the lag matching the wavelet scale, e.g. at the fourth lag for four-month wavelet scale. 


\section{Granger Causality and Impulse Response Results}

Table 2 presents the results from the impulse-response functions and the Granger causality tests when considering the effect of the interest rate differential on the spot exchange rate. The top five rows represent the results using monthly data and the bottom four rows are those of quarterly data. The Granger causality tests in Table 2 shows that the evidence of a causal relationship between the two variables is getting stronger as the time scale increases. At the sixteen month wavelet scale the interest rate differential Granger causes the exchange rate for five out of six countries, and for the four and eight quarter wavelet scales the interest rate Granger causes the exchange rate three times out of six. In contrast, Granger causality is rarely found at the shorter wavelet scales when using either monthly or quarterly data.

By examining the impulse response functions in Table 2 we can see that negative signs are dominating at the two-month wavelet scale, although they are not representing statistically significant impulse responses. This is consistent with the short-run causal relationship between the interest rate differential and the exchange rate noted in Table 1. A shift of the sign starts to be observed from the four-month wavelet scale where three positive signs are detected. The positive sign is getting dominant at the eight-month wavelet scale where four positive signs are detected, one out of which is statistically significant (for Sweden with the euro area). At the longest monthly-data wavelet scale of sixteen months we also find four positive signs with two of them representing impulse responses that are statistically different from zero. Neither of the negative signs is associated with a statistically significant impulse response at the two longest wavelet scales of the monthly data.

This pattern of more significant positive signs in the long run is also observed with the quarterly data results. At the four-quarter wavelet scale, three out of the four positive impulse responses are significant and the associated Granger causality tests indicate significance as well at the $10 \%$ significance level or lower. This tendency of positive and significant relationship from the interest rate differential to the spot exchange rate becomes slightly mitigated at the eight-quarter wavelet scale with only one significantly positive impulse response. Overall, however, it can be observed from the quarterly data result in the Table 2 that the impulse response sign is always positive whenever the Granger causality test is significant. This long-run positive relationship is, again, supported by the theoretical grounds from the earlier discussion. In addition, the tendency of the sign shift that is detected here is consistent with the theoretical causal relationships summarized in Table 1 and with the findings of the companion paper by Hacker, Kim and Månsson (2009).

The test results dealing with the other direction of the Granger causality (from the spot exchange rate to the interest rate differential) along with the results of the associated impulseresponses are presented in Table 3. As was the case with the Granger causality test results in Table 2, Table 3 shows that when using monthly data there is a stronger statistical evidence of a causal relationship between the two variables in the long run. The negative impulse response signs are dominant in the shorter wavelet scales of the monthly data (at the wavelet scale of eight months or less) while half of the cases show the positive signs at longest monthly-data wavelet scale of sixteen months, even though the only significant impulse responses has a negative sign. The only economic theories presented in Table 1 dealing the effect of exchange rate changes on interest rate differentials indicate a positive causal relationship in that direction. When considering the results of the quarterly data the evidence is less clear. There is no obvious pattern of a shift of the impulse response sign as time scale changes, and the negative signs are dominant at the longer wavelet scales of four and eight 
quarters, evidence which is not in concert with the theoretical frameworks. In general, the results obtained from the impulse-response functions are not as clear as in Table 2, when we were considering the relationship in the other direction.

Table 2: Granger causality from inter est rate differential to exchange rate

\begin{tabular}{|c|c|c|c|c|c|c|c|}
\hline \multirow[b]{2}{*}{$\begin{array}{c}\text { Wavelet } \\
\text { Scale }\end{array}$} & \multicolumn{6}{|c|}{ Country Pair } & \\
\hline & $\begin{array}{c}\text { Sweden \& } \\
\text { United } \\
\text { States }\end{array}$ & $\begin{array}{l}\text { Sweden \& } \\
\text { euro area }\end{array}$ & $\begin{array}{l}\text { Sweden } \\
\text { \& Japan }\end{array}$ & $\begin{array}{l}\text { Sweden \& } \\
\text { the United } \\
\text { Kingdom }\end{array}$ & $\begin{array}{c}\text { Sweden } \\
\& \\
\text { Norway }\end{array}$ & $\begin{array}{c}\text { Sweden } \\
\text { and } \\
\text { Switzerland }\end{array}$ & $\begin{array}{l}\text { Lags: } \\
\text { Median } \\
\text { [Range] }\end{array}$ \\
\hline $\begin{array}{l}1 \text { month } \\
\text { (using d1) }\end{array}$ & 0 & 0 & 0 & 0 & $\begin{array}{c}0 \\
(10 \%)\end{array}$ & $\begin{array}{c}0 \\
(10 \%)\end{array}$ & $\begin{array}{c}4 \\
{[2,7]}\end{array}$ \\
\hline $\begin{array}{l}2 \text { months } \\
\text { (using } d 2 \text { ) }\end{array}$ & - & - & $\begin{array}{c}- \\
(5 \%)\end{array}$ & $\begin{array}{c}-* \\
(5 \%)\end{array}$ & - & - & $\begin{array}{c}12 \\
{[12,14]}\end{array}$ \\
\hline $\begin{array}{l}4 \text { months } \\
\text { (using d3) }\end{array}$ & $-*$ & $\begin{array}{c}+ \\
(5 \%)\end{array}$ & - & + & - & + & $\begin{array}{c}9 \\
{[3,15]}\end{array}$ \\
\hline $\begin{array}{l}8 \text { months } \\
\text { (using d4) }\end{array}$ & $\begin{array}{c}+ \\
(1 \%)\end{array}$ & $+^{*}$ & $\begin{array}{c}- \\
(5 \%)\end{array}$ & - & + & + & $\begin{array}{c}8 \\
{[3,19]}\end{array}$ \\
\hline $\begin{array}{l}16 \text { months } \\
\text { (using (d5) }\end{array}$ & $\begin{array}{c}- \\
(1 \%)\end{array}$ & $\begin{array}{c}+^{*} \\
(5 \%)\end{array}$ & + & $\begin{array}{c}- \\
(10 \%)\end{array}$ & $\begin{array}{c}+ \\
(1 \%)\end{array}$ & $\begin{array}{c}+^{*} \\
(5 \%)\end{array}$ & $\begin{array}{c}5 \\
{[3,14]}\end{array}$ \\
\hline $\begin{array}{l}1 \text { quarter } \\
\text { (using d1) }\end{array}$ & 0 & 0 & 0 & 0 & 0 & 0 & $\begin{array}{c}2 \\
{[1,4]}\end{array}$ \\
\hline $\begin{array}{l}2 \text { quarters } \\
\text { (using d2) }\end{array}$ & - & $+^{*}$ & + & - & - & $\begin{array}{c}+^{*} \\
(5 \%)\end{array}$ & $\begin{array}{c}7 \\
{[2,8]}\end{array}$ \\
\hline $\begin{array}{l}4 \text { quarters } \\
\text { (using d3) }\end{array}$ & + & $\begin{array}{c}+^{*} \\
(10 \%)\end{array}$ & $\begin{array}{c}+^{*} \\
(5 \%)\end{array}$ & $\begin{array}{c}+^{*} \\
(1 \%)\end{array}$ & - & $-*$ & $\begin{array}{c}7 \\
{[2,10]}\end{array}$ \\
\hline $\begin{array}{l}8 \text { quarters } \\
\text { (using d4) }\end{array}$ & $\begin{array}{c}+ \\
(10 \%)\end{array}$ & - & $\begin{array}{c}+^{*} \\
(5 \%)\end{array}$ & $\begin{array}{c}+ \\
(10 \%)\end{array}$ & - & - & $\begin{array}{c}3.5 \\
{[3,5]}\end{array}$ \\
\hline
\end{tabular}

Note: The signs are taken from the impulse responses at lags corresponding to the wavelet scale. An asterisk on a sign indicates that the value of the impulse response is significantly different from zero (has zero outside the two standard-error confidence interval). The significance level of the Granger causality tests is provided in parenthesis. 
Table 3: Granger causality from exchange rate to interest rate differential

\begin{tabular}{|c|c|c|c|c|c|c|c|}
\hline & \multicolumn{6}{|c|}{ Country Pair } & \\
\hline $\begin{array}{l}\text { Wavelet } \\
\text { Scale }\end{array}$ & $\begin{array}{c}\text { Sweden \& } \\
\text { United } \\
\text { States }\end{array}$ & $\begin{array}{l}\text { Sweden } \& \\
\text { euro area }\end{array}$ & $\begin{array}{l}\text { Sweden } \\
\text { \& Japan }\end{array}$ & $\begin{array}{c}\text { Sweden \& } \\
\text { the United } \\
\text { Kingdom }\end{array}$ & $\begin{array}{c}\text { Sweden } \\
\& \\
\text { Norway }\end{array}$ & $\begin{array}{c}\text { Sweden } \\
\text { and } \\
\text { Switzerland }\end{array}$ & $\begin{array}{l}\text { Lags: } \\
\text { Median } \\
\text { [Range] }\end{array}$ \\
\hline $\begin{array}{l}1 \text { month } \\
\text { (using d1) }\end{array}$ & - & - & - & - & - & - & $\begin{array}{c}4 \\
{[2,7]}\end{array}$ \\
\hline $\begin{array}{l}2 \text { months } \\
\text { (using d2) }\end{array}$ & $-*$ & $\begin{array}{c}-* \\
(10 \%)\end{array}$ & $-*$ & + & - & -* & $\begin{array}{c}12 \\
{[12,14]}\end{array}$ \\
\hline $\begin{array}{l}4 \text { months } \\
\text { (using d3) }\end{array}$ & $-*$ & $\begin{array}{c}- \\
(1 \%)\end{array}$ & $-*$ & - & - & $-*$ & $\begin{array}{c}9 \\
{[3,15]}\end{array}$ \\
\hline $\begin{array}{l}8 \text { months } \\
\text { (using d4) }\end{array}$ & $\begin{array}{c}- \\
(10 \%)\end{array}$ & $\begin{array}{c}-^{*} \\
(10 \%)\end{array}$ & $\begin{array}{c}- \\
(10 \%)\end{array}$ & $\begin{array}{c}- \\
(5 \%)\end{array}$ & - & $\begin{array}{c}-^{*} \\
(10 \%)\end{array}$ & $\begin{array}{c}8 \\
{[3,19]}\end{array}$ \\
\hline $\begin{array}{l}16 \text { months } \\
\text { (using (d5) }\end{array}$ & $\begin{array}{c}+ \\
(5 \%)\end{array}$ & $\begin{array}{c}-* \\
(5 \%)\end{array}$ & $\begin{array}{c}+ \\
\\
(5 \%)\end{array}$ & $\begin{array}{c}+ \\
(10 \%)\end{array}$ & $\begin{array}{c}- \\
(1 \%)\end{array}$ & $\begin{array}{c}-^{*} \\
(5 \%)\end{array}$ & $\begin{array}{c}5 \\
{[3,14]}\end{array}$ \\
\hline $\begin{array}{l}1 \text { quarter } \\
\text { (using d1) }\end{array}$ & - & + & $-*$ & - & + & -* $^{*}$ & $\begin{array}{c}2 \\
{[1,4]}\end{array}$ \\
\hline $\begin{array}{l}2 \text { quarters } \\
\text { (using d2) }\end{array}$ & $\begin{array}{c}- \\
(10 \%)\end{array}$ & - & $\begin{array}{c}-^{*} \\
(5 \%)\end{array}$ & $\begin{array}{l}+^{*} \\
(5 \%)\end{array}$ & + & $\begin{array}{c}- \\
(5 \%)\end{array}$ & $\begin{array}{c}7 \\
{[2,8]}\end{array}$ \\
\hline $\begin{array}{l}4 \text { quarters } \\
\text { (using d3) }\end{array}$ & + & $-*$ & + & $\begin{array}{c}- \\
(5 \%)\end{array}$ & - & $\begin{array}{c}+^{*} \\
(5 \%)\end{array}$ & $\begin{array}{c}7 \\
{[2,10]}\end{array}$ \\
\hline $\begin{array}{l}8 \text { quarters } \\
\text { (using d4) }\end{array}$ & + & -* & - & - & $\begin{array}{c}- \\
(10 \%)\end{array}$ & + & $\begin{array}{c}3.5 \\
{[3,5]}\end{array}$ \\
\hline
\end{tabular}

Note: The signs are taken from the impulse responses at lags corresponding to the wavelet scale. An asterisk on a sign indicates that the value of the impulse response is significantly different from zero (has zero outside the two standard-error confidence interval). The significance level of the Granger causality tests is provided in parenthesis.

\section{Conclusions}

This paper has investigated the possibility of Granger causality at different time scales between the interest rate differential and the spot exchange rate by using LM test with White's HCCME and has considered the signs of the associated impulse responses. The empirical finding from the causality tests is that there is strong statistical evidence of a causal relationship between the two variables exists only at the longer wavelet scales when monthly data is used and/or when considering the effect of the interest rate differential on the exchange rate. At the shorter wavelet scales there is hardly any evidence in either direction and of Granger causality. Further when investigating impulse responses associated with the interest rate differential affecting the exchange rate, the results show a negative effect at the lower wavelet scales which is consistent with the Mundell-Fleming, Dornbusch, and portfolio balance models. In addition, a generally observed sign shift from negative to positive one with lengthening time scales is supported by theory and is consistent with the findings of the previous study done by Hacker, Kim and Månsson (2009). Regarding the signs corresponding to the interest rate differential affecting the exchange rate, no clear conclusion can be drawn. 


\section{References}

Akaike,H. (1971) Autoregressive model fitting for control. Ann. Inst. Statist. Math., 23(1), pp.163-180.

Almasri, A. and Shukur, G. (2003) An Illustration of the Causality Relation between Government Spending and Revenue Using Wavelet Analysis on Finnish Data. Journal of Applied Statistics, 30(5), pp.571-584.

etts, Caroline and Devereux, Michael B. (2000) Exchange rate dynamics in a model of pricing-to-market, Journal of International Economics, 52(1), pp. 215-244.

Bilson, J. F. O. (1978) The Monetary Approach to the Exchange Rate-Some Empirical Evidence. Int. Monet. Eund Staff Papers, 25(1), pp.48-75.

Branson, W. H. (1983) Macroeconomic determinants of real exchange risk. In Herrin R. J. (ed.) Managing Foreign Exchange Risk. Cambridge: Cambridge University Press.

Branson, W. H. and Halttunen H. (1979) Asset market determination of exchange rates: initial empirical and policy results. In Martin J. P. and Smith A. (eds) Trade and Payments Under Flexible Exchange Rates. London: Macmillan

Branson, W. H., Halttunen H. and Masson (1979) Exchange rates in the short-run: the dollarDeutschmark rate. European Economic Review. 10, 303-324.

Cheng B. S. (1999) Beyond the purchasing power parity: testing for cointegration and causality between exchange rates, prices, and interest rates. Journal of International Money and Finance, 18(6), pp. 911-924.

Clarida, R. and Gall, J. (1994) Sources of Real Exchange Rate Fluctuations: How Important Are Nominal Shocks? NBER WORKING PAPER.

Copeland, L. (2008) Exchange Rates and International Finance. Fifth edition. Pearson Education Limited, Harlow, England: Pearson Education Limited.

Dornbusch, R. (1976) Expectations and Exchange Rate Dynamics. Journal of Political Economy, 84(6), pp.1161-1176.

Edgerton, D. L. and Shukur, G. (1999) Testing autocorrelation in a systemwise perspective. Econometric Reviews, 18(4),pp.343-386.

Engels, C and West, K. D. (2005) Exchange Rates and Fundamentals. Journal of Political Economy, 113(3). pp.485-517.

Engle, C. (1996) The Forward Discount Anomaly and the Risk Premium: A Survey of Recent Evidence. Journal of Empirical Finance, 3(2), pp.123-192.

Fischer, I. (1930) The theory of interest. Macmillan: New York.

Fleming J. M. (1962) Domestic financial policies under fixed and floating exchange rates. IMF Staff Papers, 9(3), $369-377$.

Frenkel, J. A. (1976) A Monetary Approach to the Exchange Rate: Doctrinal Aspects and Empirical Evidence. Scandinavian Journal of Economics, 78(2), pp. 200-224.

Frenkel, J. A. (1979) On the mark: A Theory of Floating Exchange Rates Based on Real Interest Differential. The American Economic Review, 69(4), pp.610-622.

Granger, C. W. J. \& Newbold, P. (1986) Forecasting Economic Time Series, second edition Academic Press: New York.

Hacker, R. S. Kim, H., Månsson, K., (2009) The Relationship between Exchange Rate and Interest Rate Differential. Unpublished manuscript.

Hannan, E. J. \& Quinn, B. G. (1979) The determination of the order of an autoregressive. Journal of the Royal Statistical Society, B41, pp. 190-195.

Hsiao C. (1981) Autoregressive modeling and money income causality detection. Journal of Monetary Economics, 7(1), pp. 85-106.

Jarque, C. M. \& Bera, A. K. (1987) A test for normality of observations and regression residuals. International Statistical Review, 55(2), pp.163-172. 
Lane, Philip R. (2001) The New Open Economy Macroeconomics: a Survey. Journal of International Economics, 54(2) pp. 235-266.

Lastrapes, W. D. (1992) Sources of Fluctuations in Real and Nominal Exchange Rates. Review of Economics and Statistics, 74(3), pp.530 - 539.

Mallat S.G., (1989) A theory for multiresolution signal decomposition: the wavelet representation. Pattern Analysis and Machine Intelligence, IEEE Transactions. 11(7), pp. 674-693.

McCallum, B. (1994) A Reconsideration of the Uncovered Interest Parity. Journal of Monetary Economics, 33(1), pp.105-132.

Mundell, R. A. (1962) The appropriate use of monetary and fiscal policy under fixed exchange rates. IMF Staff Papers, 9(1), 70-77.

Månsson, K., Shukur, G.,(2009) Granger causality test in the presence of spillover effects. Communication in Statistics - Simulation and Computation, 38(10), pp.2039-2059.

Obstfeld, M. and Rogoff, K. (1995) Exchange Rate Dynamics Redux. The Journal of Political Economy, 103(3), pp.624-660.

Percival, D. B. B. and Mjofeld, H. O. (1997) Analysis of subtidal coastal sea level fluctuations using Wavelets. Journal of the American Statistical Association, 92(439), pp.868-880.

Percival, D. B. and Walden, A. T. (2000) Wavelet Methods for Time Series Analysis. Cambridge University Press: Cambridge.

Percival, D. B., Sardy, S. and Davison A. C. (2000) Wavestrapping time series: Adaptive wavelet-based bootstrapping. Nonlinear and Nonstationary Signal Processing, pp.442-471, Cambridge University Press.

Ramsey, J. B. and Lampart, C. (1998) Decomposition of Economic Relationships by Timescale Using Wavelets. Macroeconomic Dynamics, 2(1), pp.49-71.

Schwartz, G. (1978) Estimating the dimension of a model. Annals of Statistics, 6(2), pp.461464. 